\title{
SEISMIC EARTH PRESSURE EXERTED ON RETAINING WALLS UNDER A LARGE SEISMIC LOAD
}

\author{
Kenji Watanabe ${ }^{\text {i) }}$, Junichi Koseki ${ }^{\text {ii) }}$ and Masaru Tateyama ${ }^{\text {iii) }}$
}

\begin{abstract}
In recent years, serious damage has been done to retaining structures because of large earthquakes. In order to establish practical methods for evaluating the seismic earth pressure, which is one of the important external forces acting on retaining structures during large earthquakes, a series of shaking table tests was conducted on retaining wall (RW) models. The experiments revealed that the seismic active earth pressure was considerably smaller than that obtained by the Mononobe-Okabe theory, particularly under a large seismic load. Furthermore, it was demonstrated that the seismic earth pressure had an upper limit, which was determined by the force equilibrium of the soil wedge at the critical state when the RW lost its stability. On the basis of the test results, a new method to evaluate the seismic earth pressure for practical designs under a large seismic load has been suggested. This proposed method provides a reasonable earth pressure as well as an angle of failure plane, those of which depend on the seismic stability of the retaining wall. It has been confirmed that earth pressure obtained by the proposed method agrees well with the measured seismic earth pressure exerted on several retaining walls with different degrees of stability.
\end{abstract}

Key words: bearing capacity, design, (failure plane), retaining wall, (seismic earth pressure), shaking table test (IGC: $\mathrm{E} 5 / \mathrm{E} 8)$

\section{INTRODUCTION}

In recent years, serious damage has been done to retaining walls (RWs) because of large earthquakes. The Hyogo-ken Nambu earthquake, which struck Japan on January 17,1995 , for example, caused serious damage to conventional masonry and the concrete gravity-type RWs of railway embankments (Tatsuoka et al., 1996).

Seismic earth pressure, which is one of the important external forces acting on RWs during earthquakes, is largely affected by the dynamic interaction between the walls and the backfill; the detailed mechanism of this effect has not yet been clarified well. In current seismic design procedures, the Mononobe-Okabe (M-O) theory (Okabe, 1924; Mononobe and Matsuo, 1929) is often used to evaluate the seismic earth pressure. Although this theory is simply based on the pseudo-static approach, many researchers have mentioned that the theory is only applicable under a small seismic load (around $200 \mathrm{gal}$ ). This has been confirmed through shaking table model tests where the dynamic response of RWs was negligible (Ichihara and Matsuzawa, 1973; Sherif et al., 1982). However, Whitman (1990) pointed out that these model tests were carried out under conditions similar to those assumed in the M-O theory, and that this is why the experimental results agreed mostly with the M-O theory.
The peak ground acceleration that was recorded during recent major earthquakes in Japan approached or exceeded 800 gal, particularly after the 1995 Hyogo-ken Nambu earthquake. Therefore, in Japan, it has become necessary to design important earth structures against such high levels of near-fault earthquake effects. Using such a large seismic load, we observe that the M-O theory often derives an unrealistically large seismic earth pressure, and sometimes, the seismic load exceeds the applicable limit of this theory. This often causes practical problems when designing retaining structures or evaluating the seismic stability of an existing retaining structure. Therefore, it has become necessary to evaluate the seismic earth pressure rationally under a large seismic load in order to establish a practical design procedure for retaining structures.

In recent years, a modified M-O method (Koseki et al., 1998a), that considers the effects of strain localization and strain softening in the post-peak behavior of wellcompacted backfill soils, has been adopted for the design of railway structures and highway bridges against high seismic loads (RTRI, 1999; JRA, 2002). On the other hand, Watanabe et al. $(1999,2003)$ found through shaking table model tests that the seismic earth pressure is largely affected by the dynamic response of RWs. Furthermore, the seismic earth pressure measured under a large

i) Assistant Senior Researcher, Structures Technology Division, Railway Technical Research Institute, Japan (nabeken@rtri.or.jp).

i) Professor, Institute of Industrial Science, University of Tokyo, Japan.

iii) Director, Structures Technology Division, Railway Technical Research Institute, Japan.

The manuscript for this paper was received for review on May 21, 2010; approved on March 31, 2011.

Written discussions on this paper should be submitted before January 1, 2012 to the Japanese Geotechnical Society, 4-38-2, Sengoku, Bunkyo-ku, Tokyo 112-0011, Japan. Upon request the closing date may be extended one month. 
seismic load was smaller than that obtained with the modified M-O method using the maximum base acceleration and the peak value of the backfill soil strength.

Several other researchers have conducted shaking table model tests and have suggested new methods for predicting the seismic earth pressure or the residual displacement of RWs. For example, Nakamura (2006) conducted centrifuge shaking tests using gravity-type RW models. These shaking tests revealed that there is a phase lag between the wall and the backfill, while the M-O theory assumes that there is no phase difference between the motion of the RW and the backfill. The seismic earth pressure and its distribution were strongly affected by this phase difference, and the distribution measured in this study was not a triangular distribution. This runs contrary to the M-O theory. Okamura and Matsuo (2002) proposed a new calculation method for the seismic plastic displacement of RWs. A macroscopic failure surface and a plastic displacement potential in the general load space were considered in this method. The authors mentioned that it was necessary to apply an appropriate seismic earth pressure for assessing the fully coupled displacement of RWs.

To the best of our knowledge, the detailed mechanism of the seismic earth pressure, especially under a large earthquake load, has not been investigated sufficiently in any literature. In addition, although seismic earth pressure is caused by the dynamic interaction between the backfill soil and the RWs, the deformation of the backfill during shaking has not been measured adequately in these tests.

In this study, therefore, a series of shaking table tests using gravity-type RWs was performed, and the seismic earth pressure measured under a large earthquake load was compared with that obtained by the M-O theory. Furthermore, an image processing system using a highspeed CCD camera was set up to make it possible to measure the dynamic deformation of the backfill soil. The relationship between the seismic earth pressure and the deformation characteristics of the backfill, especially the formation of the failure plane, was precisely investigated by applying this system to shaking table tests. On the basis of these test results, a new method to predict the seismic earth pressure under a large earthquake load was proposed.

\section{TESTING PROCEDURES}

\section{Model of Retaining Wall and Backfill}

Model tests were conducted with a shaking table at the Railway Technical Research Institute, Japan. A rigid soil container (length: $2050 \mathrm{~mm}$, width: $600 \mathrm{~mm}$ and height: $1400 \mathrm{~mm}$ ) was fixed to this table. A gravity-type of RW model (height: $530 \mathrm{~mm}$ and weight: $938 \mathrm{~N}$ ) was used in this study (Fig. 1). The geometric shape of this model was set by referring to that of typical ones having a height of about $5 \mathrm{~m}$ in Japan, while reducing the size to a scale of almost one-tenth. In order to adjust the self-weight of the RW model, extra weights were added near the center of gravity of the RW. The total amount of extra weight was set so that the minimum critical seismic coefficient of the RW model, which was set on the subsoil model made of sand (Case 1 in Table 1), would yield a safety factor of unity against sliding, overturning and bearing capacity failure falls in the range from 0.3 to 0.4 , when the relevant design procedures were followed using the limitequilibrium and pseudo-static approach. This critical seismic coefficient almost corresponds to that of the gravity-type RW which is generally designed for railway structures in Japan. As shown in Fig. 1, both normal and shear components of the thrust force were monitored with a number of small two-component load cells set along the center line of the wall surface. The backfill model was made of air-dried Toyoura sand $\left(D_{50}=0.23\right.$ $\mathrm{mm}, G_{\mathrm{s}}=2.648, e_{\max }=0.977$ and $e_{\min }=0.609$ ). The sand layers were prepared using a sand hopper and by keeping the falling height constant. An average relative density of $90 \%$ was achieved with this method.

In order to minimize the friction between the edge of the RW models and the sidewall of the soil container, a
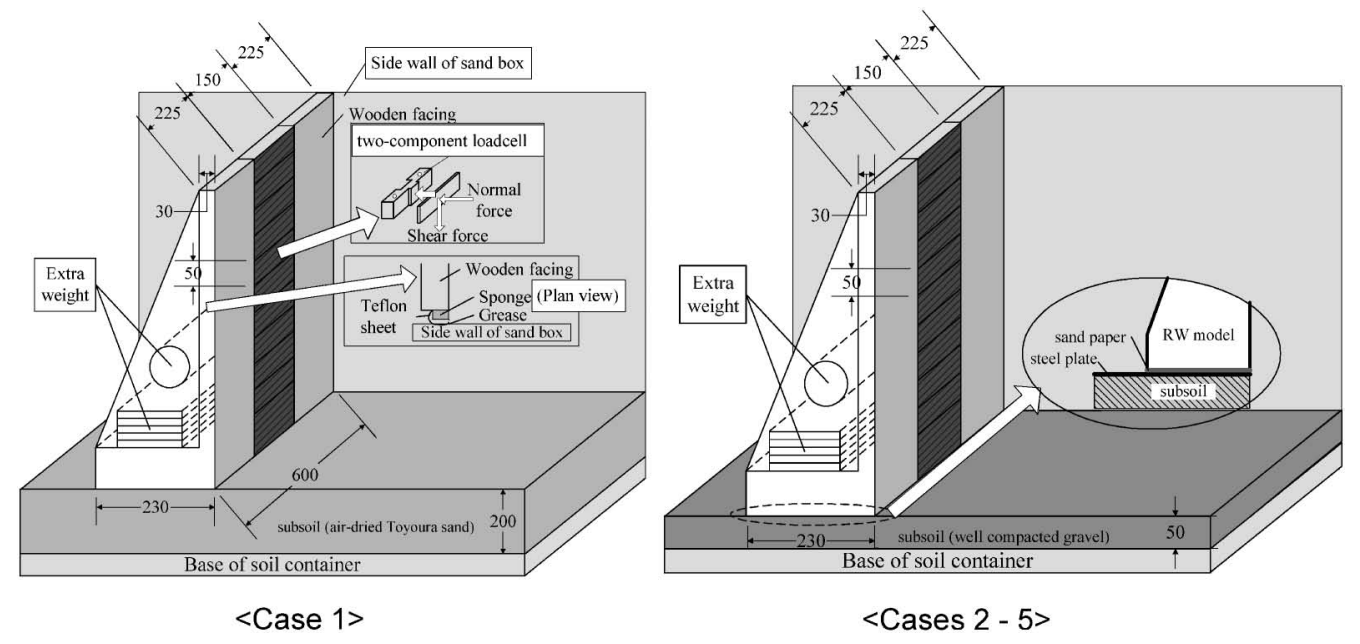

Fig. 1. Details of gravity-type retaining wall model (unit in $\mathbf{m m}$ ) 
Table 1. Subsoil condition and input earthquake motion of all tests

\begin{tabular}{c|c|c|c|c}
\hline \multirow{2}{*}{$\begin{array}{c}\text { Name } \\
\text { of tests }\end{array}$} & \multicolumn{2}{|c|}{ Subsoil condition } & \multicolumn{2}{c}{ Input earthquake motion } \\
\cline { 4 - 5 } & $\begin{array}{c}\text { Subsoil } \\
\text { model }\end{array}$ & $\begin{array}{c}\text { Maximum friction } \\
\text { angle of base } \\
\text { footing, } \delta_{\text {footing }}\end{array}$ & $\begin{array}{c}\text { Predominant } \\
\text { frequency }\end{array}$ & $\begin{array}{c}\text { Number of } \\
\text { shaking }\end{array}$ \\
\hline Case 1 & Sand $(20 \mathrm{~cm})$ & - & $5 \mathrm{~Hz}$ & 2 \\
\hline Case 2 & \multirow{2}{*}{$\begin{array}{c}\text { Well-graded } \\
\text { gravel }(5 \mathrm{~cm})\end{array}$} & $31^{\circ}$ & $5 \mathrm{~Hz}$ & 2 \\
\cline { 1 - 1 } Case & steel plate & $34^{\circ}$ & $2 \mathrm{~Hz}$ & 1 \\
\cline { 1 - 1 } Case 4 & & $36^{\circ}$ & $10 \mathrm{~Hz}$ & 5 \\
\cline { 1 - 1 } Case 5 & & & &
\end{tabular}

sponge, a Teflon sheet and grease were used, as schematically shown in Fig. 1. The leakage of sand from the gap between the RW models and the soil container could completely be prevented by this method. Watanabe et al. (2003) summarized the details of the model preparation and the similitude adopted in these shaking table tests.

Table 1 shows a list of all the tests performed in the present study. The subsoil model and the predominant frequency of the input motion were different among these tests. The subsoil model in Case 1 was made of air-dried Toyoura sand, and the RW model was set directly on this subsoil model, while the subsoil model was made of wellcompacted gravel in Cases 2-5. An iron plate, which was covered with sand paper, was fixed on the subsoil model in Cases 2-5 so that the major failure mode of the RW becomes lateral sliding (Fig. 1). To study the effect of the seismic stability of the RW against sliding due to seismic earth pressure, sand paper with a large friction (\#40) was employed in Case 5, while other sand paper $(\# 80$ ) was employed in Cases 2-4. The maximum friction angle between the bottom of the base footing and the iron plate, $\delta_{\text {footing, }}$, is also given in Table 1 . This friction angle was obtained by conducting lateral loading tests on the RW under static conditions. Note that the larger friction angle for Case 4, compared to that for Cases 2 and 3, was due mainly to the sand paper which was changed to the new one for Case 4.

In order to visually observe the deformation of the backfill soil, horizontal layers of black-dyed Toyoura sand with a thickness of $5 \mathrm{~mm}$ were prepared at a vertical spacing of $100 \mathrm{~mm}$ adjacent to the transparent sidewall of the sand container (Fig. 2). This black-dyed sand was different from the black target for the image processing that would be introduced later. After filling the sand, the surface of the backfill was trimmed to the prescribed geometry, and a surcharge of $1 \mathrm{kPa}$ was applied by placing lead shots on the surface of the backfill.

As shown in Fig. 3, a number of displacement transducers and accelerometers were installed in order to measure the response of the RW and the backfill. All sensors were placed along the centerline of the soil container in order to reduce the effect of the sidewall friction of the sand container (width: $600 \mathrm{~mm}$, Fig. 1). Watanabe et al. (2003) confirmed that the effect of the sidewall friction on the measured value (i.e., the response acceleration, the

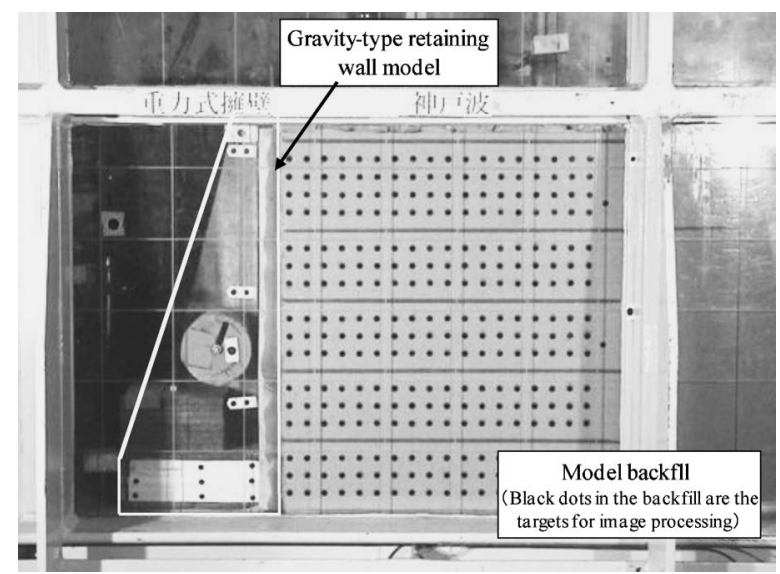

Fig. 2. Front view of the model

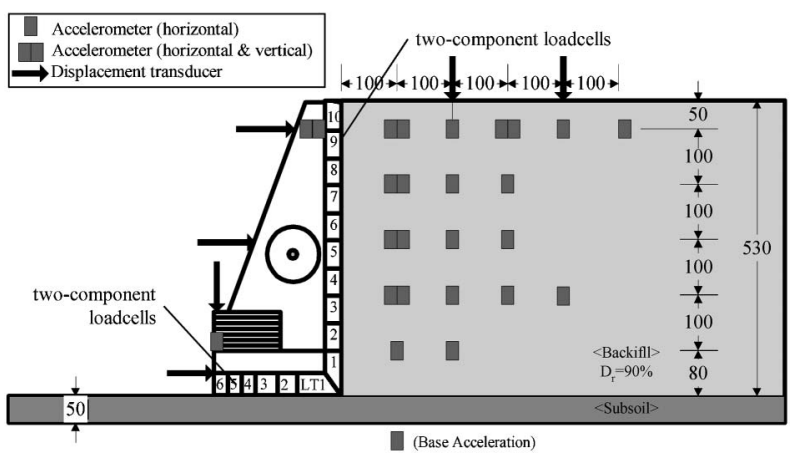

Fig. 3. Location of transducers (Cases 2-5, unit in mm)

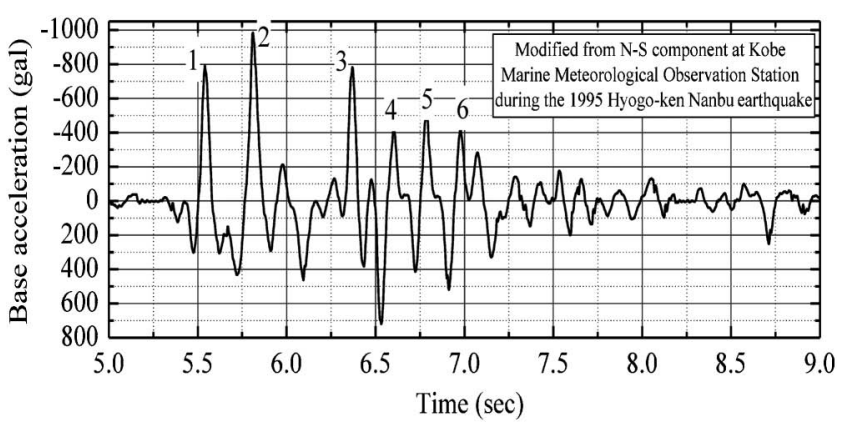

Fig. 4. Typical time history of base acceleration

displacement and so on) measured along the center line of the soil container was negligible. The accelerometers in the backfill were mainly arranged inside the soil wedge by considering where the failure plane was supposed to form.

\section{Application of Seismic Loads}

Seismic loads were applied by shaking the soil container horizontally by means of irregular base acceleration. A strong motion that was recorded as an N-S component at the Kobe Marine Meteorological Observation Station during the 1995 Hyogo-ken Nambu earthquake was used as the base acceleration (Fig. 4). Its amplitude and time 
scale were adjusted among the several shaking table tests so that the base acceleration had the prescribed maximum amplitude (approximately 970 gal) with predominant frequencies of 2, 5 and $10 \mathrm{~Hz}$. These predominant frequencies were evaluated on the basis of the Fourier spectrum of the base acceleration. The model was subjected to this irregular excitation several times until the wall movement became considerably large. Table 1 shows the predominant frequency and the number of shaking tests for each case.

\section{Image Processing Ssystem}

An image processing system, using a high-speed CCD camera, was established to make it possible to measure the two-dimensional deformation of the backfill. The two-dimensional movement of the targets set in the backfill soil adjacent to the transparent hard glass sidewall can automatically be measured by this system. A number of rivets made of aluminum with a black circular flat edge were used as targets; they were set in the backfill soil at a horizontal spacing of $25 \mathrm{~mm}$ and a vertical spacing of 25

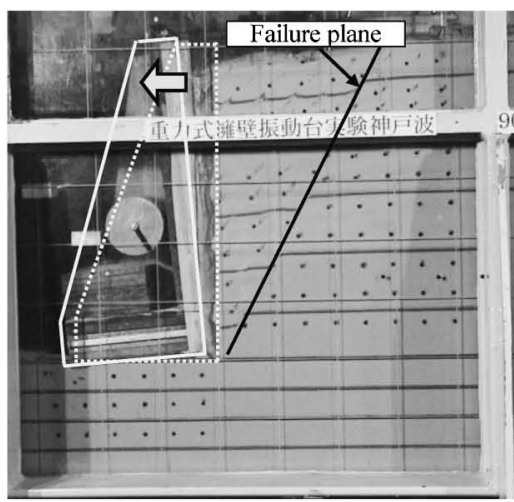

$<$ Case $1>$

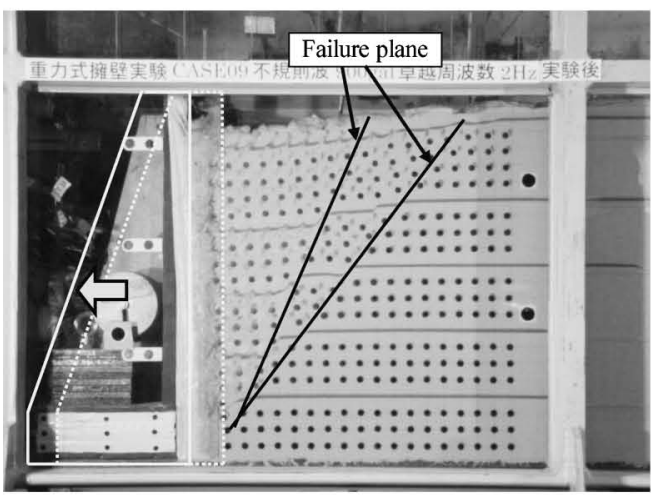

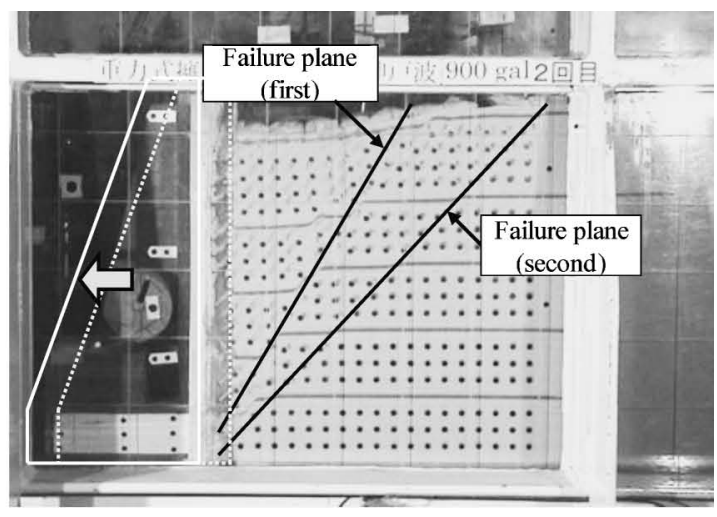

$<$ Case $2>$

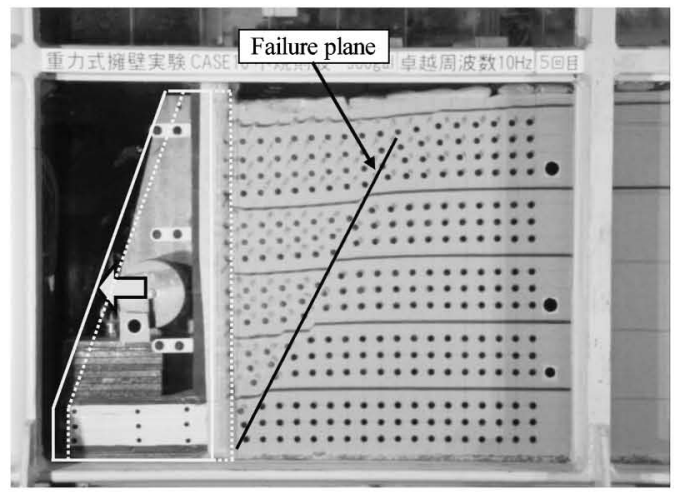

$<$ Case $4>$

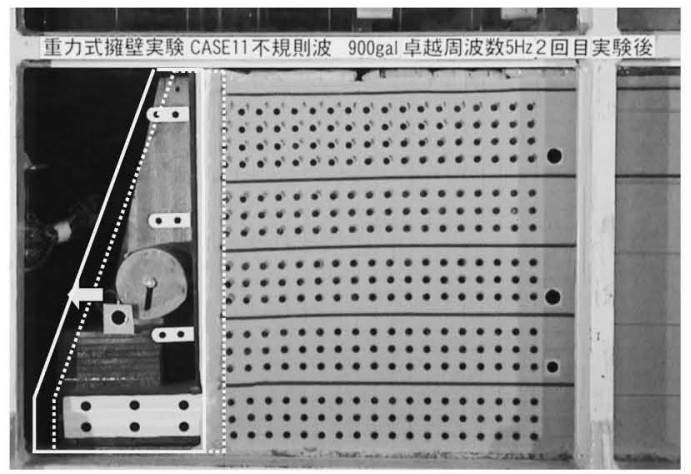

$<$ Case $5>$

Fig. 5. Residual displacement of wall and formation of failure planes 
$\mathrm{mm}$ or $50 \mathrm{~mm}$ (Fig. 2). In order to ensure permanent contact between the glass and the targets, thereby following the surrounding sand movement, silicon grease was smeared between the targets and the glass.

The high-speed CCD camera was positioned approximately $2 \mathrm{~m}$ away from the sidewall. According to the calibration of this system, the actual accuracy was approximately 0.3 pixels, which corresponds to $1 \mathrm{~mm}$ in the case of the present testing conditions.

The maximum frame rate of the high-speed CCD camera was $200 \mathrm{~Hz}$, and the acquisition time was approximately $50 \mathrm{~s}$, both of which are sufficient for the shaking table tests in this study. Watanabe et al. (2005) have summarized the details of this image processing system.

\section{TEST RESULTS AND DISCUSSION}

\section{Failure Pattern of Models}

Figure 5 shows the residual displacement of the wall and the residual deformation of the backfill, which were observed at the end of the final shaking step. The major failure pattern of the RW in Case 1 was overturning, which was associated with the bearing capacity failure of the subsoil, while that of the RW in Cases 2, 3, 4 and 5, where the RW was set on well-compacted gravel, was sliding. In Cases 1, 2, 3 and 4, the formation of a failure plane was clearly observed, while this formation was not very clear in Case 5. This may be due to the amount of residual displacement of the RW model. Since the RW model in Case 5 was set on an iron plate with a large resistance against sliding (Table 1), the residual displacement of the RW was smaller than that in other cases, resulting in the small strain localization in the backfill. The same tendency was also observed for the first and second shaking steps in Case 4 where the residual displacement of the RW was smaller than that in Cases 2 and 3. This is because the displacement of the RW tends to increase slowly with an increase in the predominant frequency of shaking where the duration of the peak load condition in the active state is limited.

Figure 6 shows the location of the failure plane in Cases 2 and 3 measured at the centerline of the sand con- tainer. This was measured during the process of removing the backfill soil after the final shaking step (Fig. 7). It should be noted that the angle of the failure plane measured from the horizontal direction was approximately $3^{\circ}$ to $7^{\circ}$ larger for the transparent sidewall than that measured at the centerline of the sand container. This indicates that the deformation pattern of the backfill soil just beside the sidewall was affected by the sidewall friction to some extent. Watanabe et al. (2003) confirmed that the effect of the sidewall friction on the response of the model at the centerline of the soil container $(600 \mathrm{~mm}$ in width) was not significant. It is also confirmed that failure planes formed simultaneously near the transparent sidewall and along the centerline of the soil container. This was confirmed with an electric sensor, which can detect the formation of a failure plane, arranged horizontally in the backfill where the failure plane was supposed to form. Based on these results, the moment of the formation of the failure plane was determined by an observation through the transparent sidewall, while the angle of the failure plane measured at the centerline of the soil con-

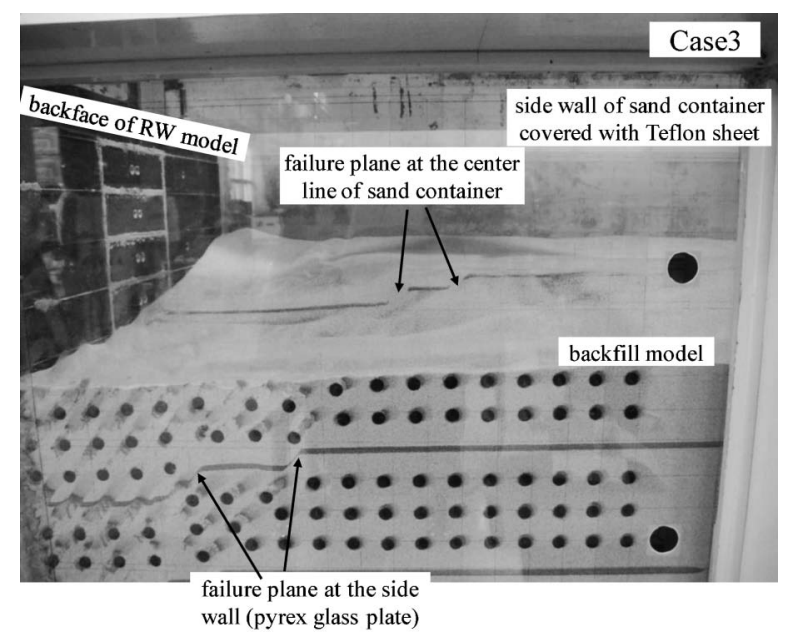

Fig. 7. Location of failure planes observed at side wall and center line of sand container (observed during the process of removing the backfill soil after shaking)
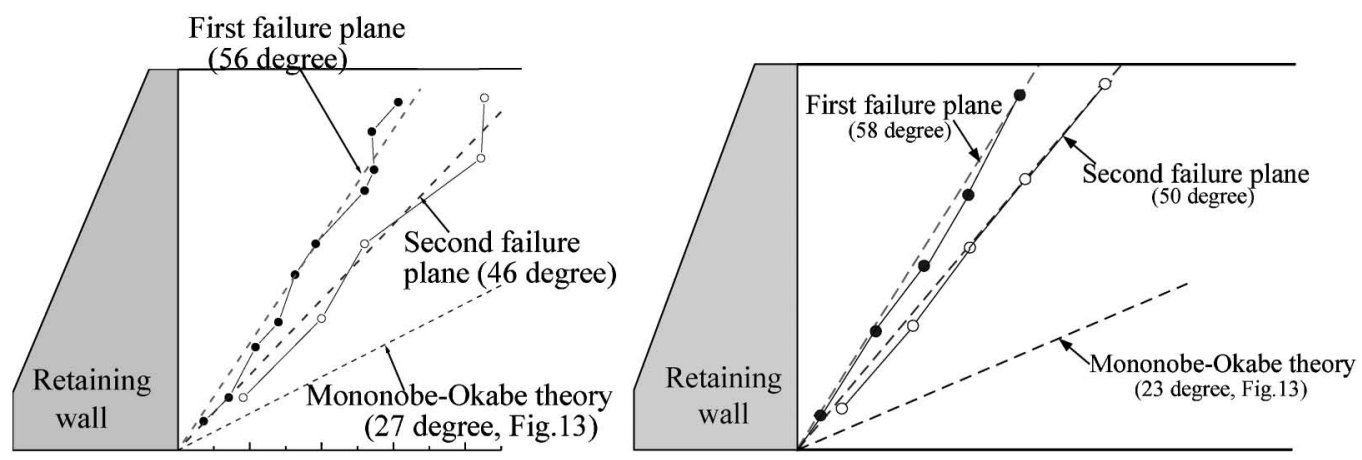

$<$ Case $2>$

$<$ Case $3>$

Fig. 6. Location of failure planes observed at center line of sand container 
tainer was employed for a later study.

It should also be noted that the location of the failure plane was steeper than the theoretical value, which was obtained by applying the maximum base acceleration and the peak value of the backfill soil strength to the M-O theory (Fig. 6). This result is consistent with the actual observation of the failure plane formed in the backfill of a damaged railway RW after the 1995 Hyogo-ken Nambu earthquake (Fig. 8). This will be discussed in detail later.

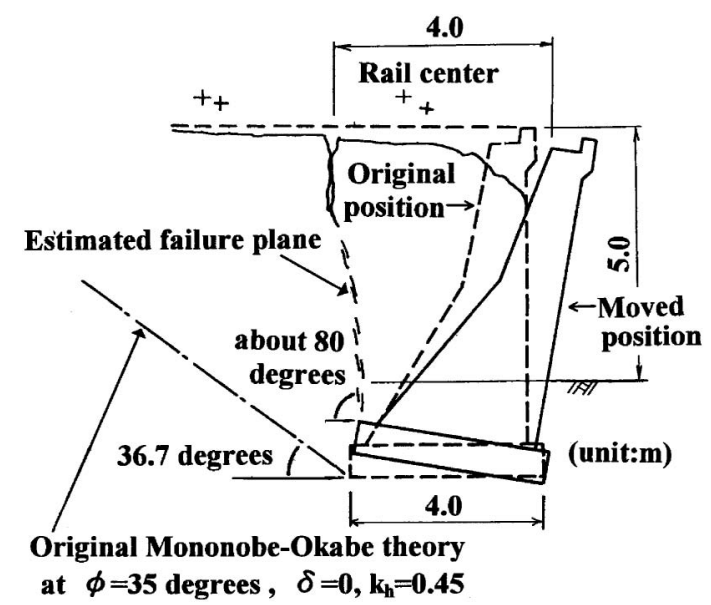

Fig. 8. Failure plane formed in backfill of damaged railway retaining wall after 1995 Hyogo-ken Nambu earthquake (Tatsuoka et al. 1998)

\section{Dynamic Response Characteristics of Backfill}

Figures 9 and 10 show the response distribution and the phase lag distribution of the response acceleration in the backfill in Cases 2, 3 and 4 when the largest inertia force was oriented toward the active direction during the first shaking test (Point 2 in Fig. 4). The response distribution shown in Fig. 9 is the ratio of the peak response acceleration of the backfill to the peak of the base acceleration. The phase lag distribution shown in Fig. 10 is the time lag between the response acceleration and the base acceleration when it reached the maximum. The location of the failure plane observed at the centerline of the sand container after the final shaking step was also shown in these figures. It can be seen from these figures that the response acceleration was smaller and that the phase lag was larger in the soil wedge above the failure plane in Cases 2 and 3. These types of behavior are possibly due to the formation of the failure plane, resulting in the sliding of the soil wedge along the failure plane. On the other hand, such a clear change in phase lag or response acceleration cannot be seen in Case 4, where the location of the failure plane was not so clear at the first shaking.

Figure 11 shows the time history of the horizontal and the vertical response accelerations of the soil wedge in Case 2. The response accelerations of the soil wedge were obtained by taking the average output of all the accelerometers located inside the soil wedge. As shown in Fig. 12, the soil wedge was divided into several wedges considering the arrangement of the accelerometers, and the horizontal response acceleration, $a_{\mathrm{h} \text {, res }}$, was defined as follows:

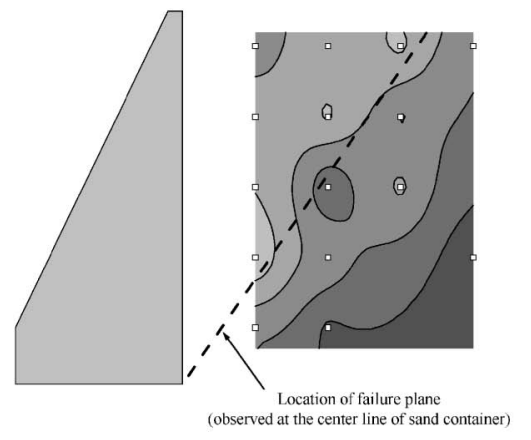

Case 2

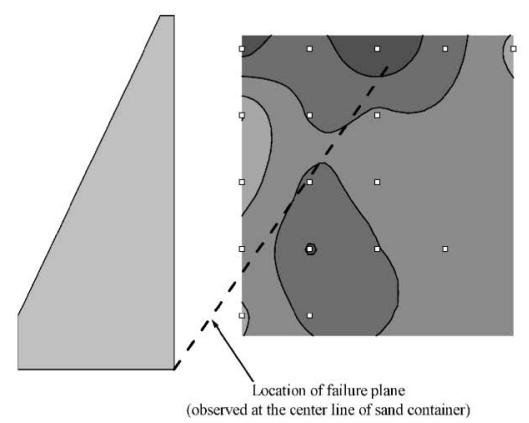

Case 4

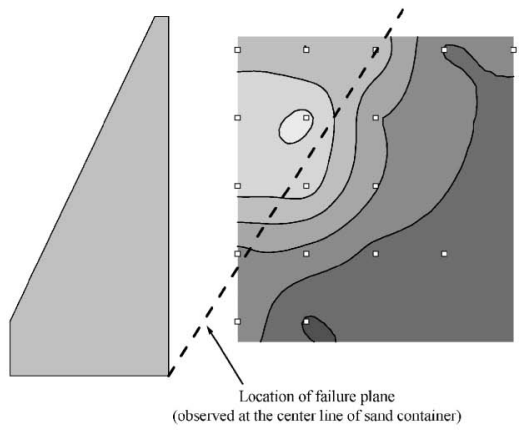

Case 3

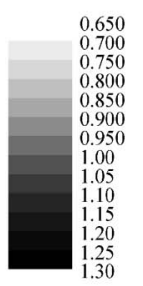

Ratio of response acceleration to base

Fig. 9. Response distribution of peak acceleration in backfill 


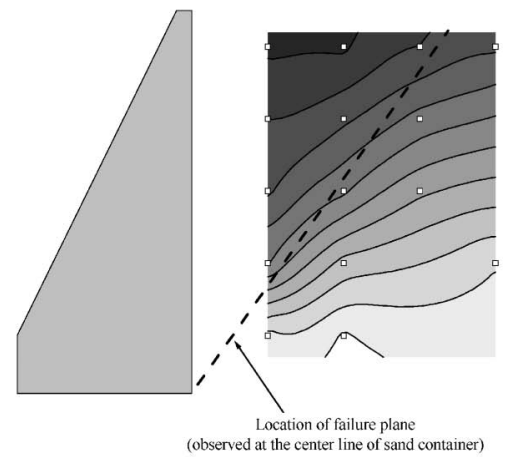

Case 2

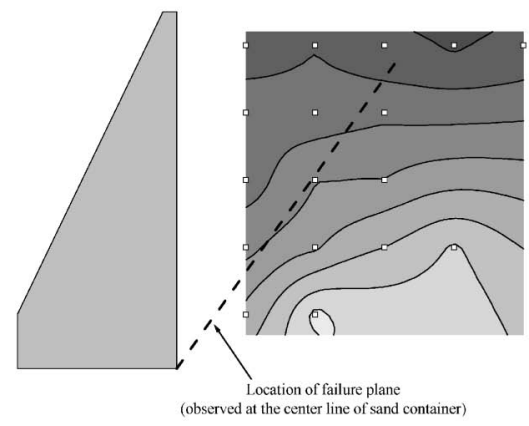

Case 4

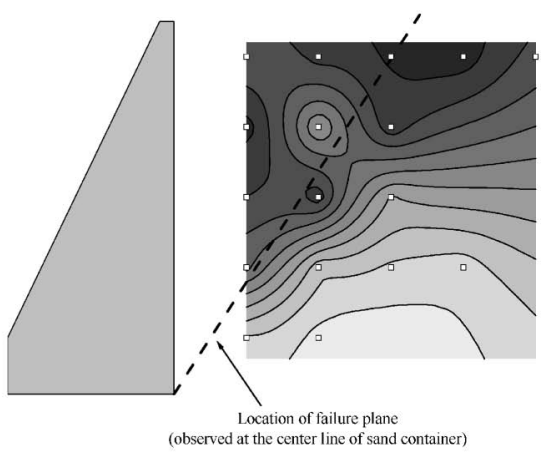

Case 3

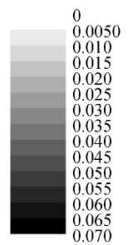

Time lag of response acceleration (sec)

Fig. 10. Phase lag distribution of response acceleration in backfill
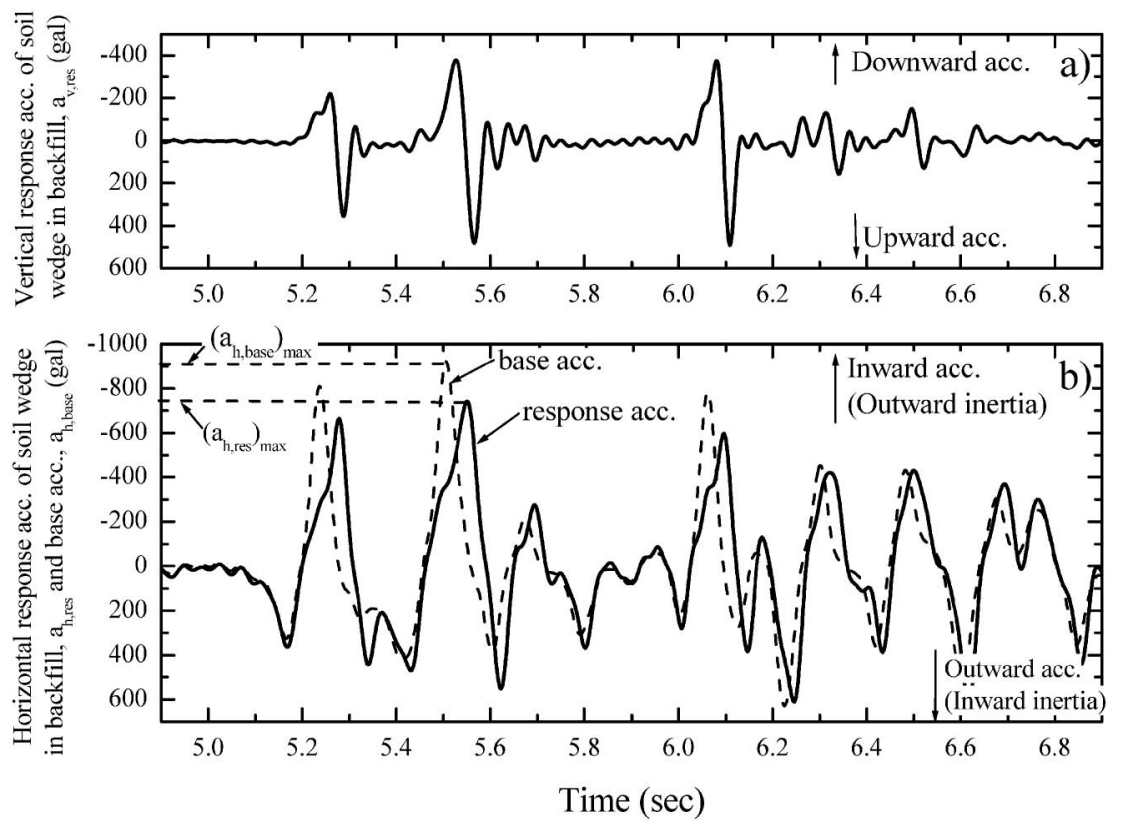

Fig. 11. Typical response acceleration of soil wedge above failure plane (Case 2)

$$
a_{\mathrm{h}, \mathrm{res}}=\frac{\sum a_{\mathrm{h}, \mathrm{i}} \times A_{\mathrm{i}}}{A_{\text {total }}}
$$

where $a_{\mathrm{h}, \mathrm{i}}$ is the output of each accelerometer inside the soil wedge, $A_{\mathrm{i}}$ is the weight of each wedge and $A_{\text {total }}$ is the total weight of the soil wedge. For example, seven accelerometers (No. 3, 4, 5, 7, 8, 10 and 13 in Fig. 12) were employed for obtaining $a_{\mathrm{h}, \text { res }}$, in Case 2 . The accelerome- ters, which were employed for obtaining the value of $a_{\mathrm{h}, \text { res}}$, depended on the location of the failure plane for each test. It can be seen from Fig. 11 that the peak horizontal response acceleration, $\left(a_{\mathrm{h}, \mathrm{res}}\right)_{\max }$, inducing the outward inertia, was smaller than the peak horizontal base acceleration, $\left(a_{\mathrm{h}, \text { base }}\right)_{\max }$, and a certain phase lag can be observed between the moment when both of them reached the maximum. These results were also due to the 


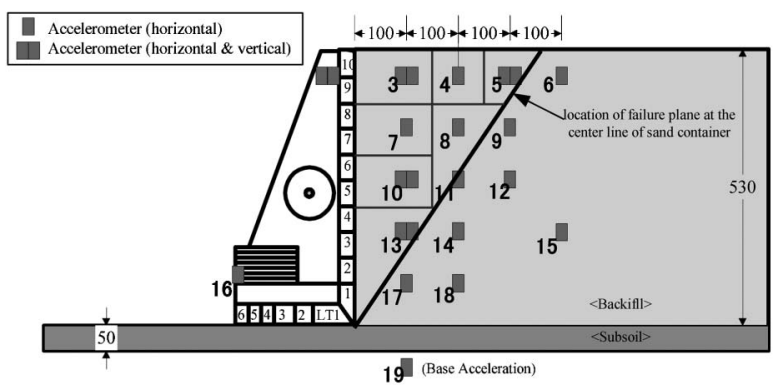

Fig. 12. Division of soil wedge (Case 2, unit in $\mathrm{mm}$ )

sliding of the soil wedge along the failure plane. It should also be noted that the horizontal response of the soil wedge above the failure plane was accompanied by its vertical response. When the outward inertia force was acting on the soil wedge, the soil wedge was also subjected to a vertical upward inertia force (i.e., downward acceleration) at the beginning, which was reversed into a downward inertia force (i.e., upward acceleration) at a later stage. A similar tendency was also observed in other tests with a different predominant frequency of shaking after the formation of a failure plane. These tests revealed that the dynamic response characteristics of the backfill were strongly affected by the formation of the failure plane in the backfill. The formation of the failure plane was precisely investigated by an image processing system. This will be discussed later.

\section{Comparison between $M-O$ Theory and Experimental Value}

Figure 13 shows the relationship between the angle of the failure plane measured from the horizontal direction

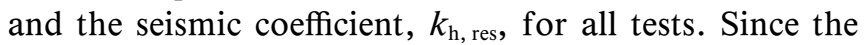
$\mathrm{M}-\mathrm{O}$ theory considered the force equilibrium of the soil wedge, the seismic coefficient was obtained from the peak horizontal response acceleration of the soil wedge. It was defined as follows:

$$
k_{\mathrm{h}, \mathrm{res}}=\left(a_{\mathrm{h}, \mathrm{res}}\right)_{\max } / g
$$

where $\left(a_{\mathrm{h}, \mathrm{res}}\right)_{\max }$ is the single amplitude of the maximum response acceleration of the soil wedge in the active state inducing outward inertia, as typically shown in Fig. 11, and $g$ is the gravitational acceleration. Theoretical relationships based on the $\mathrm{M}-\mathrm{O}$ theory are also shown in this figure. In order to obtain these theoretical relationships, the shear resistance angle $\phi$ of the backfill was set to be equal to $\phi_{\text {peak }}\left(=51^{\circ}\right)$ obtained from the relevant plane strain compression (PSC) tests which were conducted under a low confining pressure $(10 \mathrm{kPa})$ (Koseki et al., 1998b). Frictional angle $\delta_{\text {wall }}$ at the interface between the backfill and the wall facing with sand paper was set to be equal to $3 / 4 \phi_{\text {peak }}$ (Koseki et al., 1998b). A value of around $3 / 4$ was obtained as the ratio of the simple shear peak friction angle $\phi_{\mathrm{ss}}=\arctan \left(\tau / \sigma_{\mathrm{n}}\right)_{\max }$, to the peak angle of $\phi_{\text {peak }}=\arcsin \left\{\left(\sigma_{1}-\sigma_{3}\right) /\left(\sigma_{1}+\sigma_{3}\right)_{\text {max }}\right\}$ from the PSC tests having a vertical $\sigma_{1}$ direction, both values were obtained for air-pluviated Toyoura sand (Tatsuoka et al., 1991). It

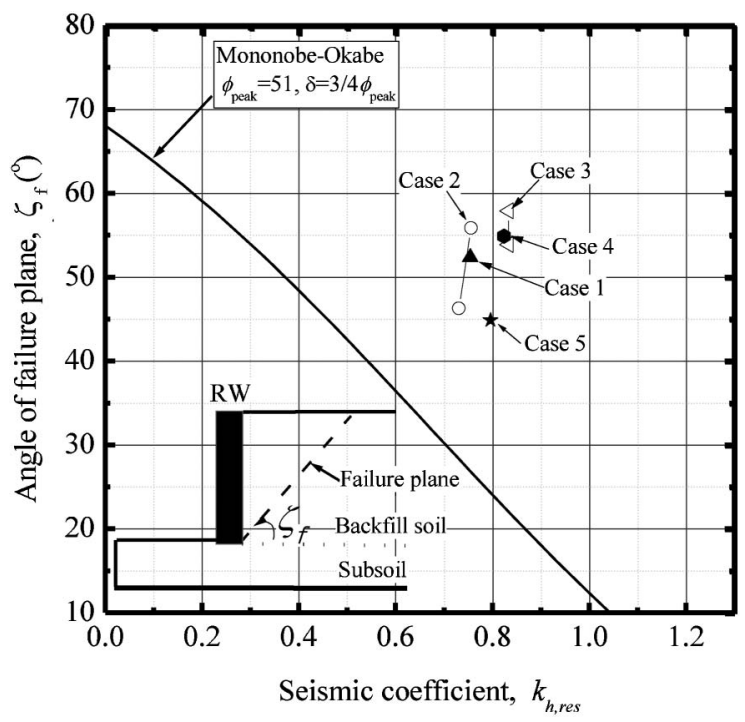

Fig. 13. Relationship between angle of failure plane and seismic coefficient

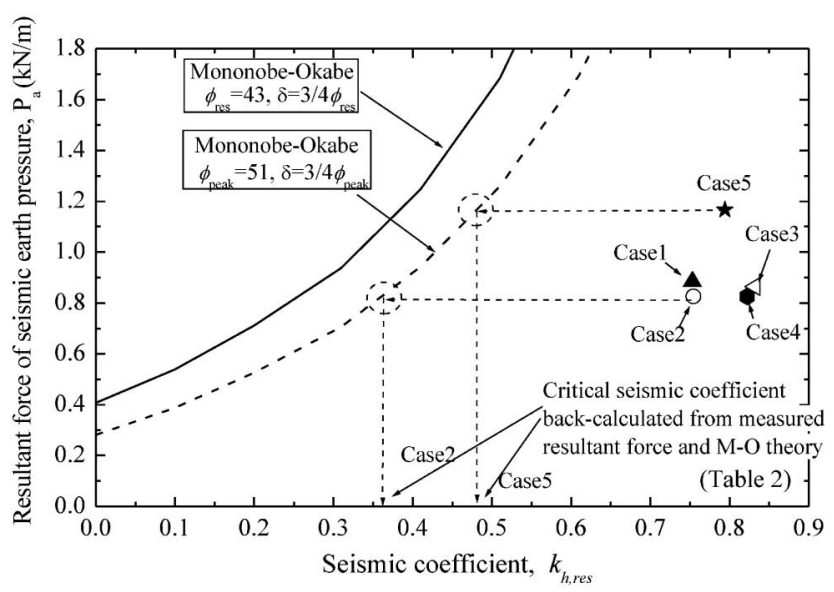

Fig. 14. Relationship between resultant force of seismic earth pressure and seismic coefficient

can be seen from this figure that the angle of the observed failure plane was considerably larger than that calculated by the M-O theory, especially under a large seismic load condition.

Figure 14 shows the relationship between the resultant force of the seismic earth pressure, $P_{\mathrm{a}}$, and the seismic coefficient, $k_{\mathrm{h} \text {, res }}$, for all tests. The resultant force was evaluated by integrating normal and shear stresses measured with ten load cells along the depth of the facing, which include the initial values measured before the start of the shaking tests. Since the inertia force of the cover plate of each load cell was measured by the load cell unintentionally (Fig. 1), it was removed by considering the weight of the cover plate and the response acceleration of the RW at each height. This inertia effect of the selfweight of the cover plate was precisely investigated by shaking the RW model fixed to the soil container without the backfill. The $P_{\mathrm{a}}$ value was obtained at the moment when $\left(a_{\mathrm{h}, \text { res }}\right)_{\max }$ was mobilized, and it was corrected by 
dividing it with a factor of " $1+a_{\mathrm{v} \text {, res }} / g$," where $a_{\mathrm{v} \text {, res }}$ is the vertical acceleration of the soil wedge obtained at the same moment as above (defined as positive when a downward inertia force is induced). For the sake of comparison, theoretical relationships based on the $\mathrm{M}-\mathrm{O}$ theory considering the peak condition of $\phi=\phi_{\text {peak }}\left(=51^{\circ}\right)$ and the residual condition of $\phi=\phi_{\text {res }}\left(=43^{\circ}\right)$ are also shown in this figure. This figure reveals that the resultant force of the seismic earth pressure under a large earthquake load is considerably smaller than that obtained by the M-O theory. If the seismic coefficient was obtained by the maximum of the base acceleration $\left(a_{\mathrm{h}, \text { base }}\right)_{\max }$, the difference between the value obtained using the M-O theory and the measured value increases. It should be noted that higher seismic earth pressure was measured in Case 5 than in Case 2, although the model was subjected to almost the same intensity and predominant frequency of shaking. This is due to the higher seismic stability of the RW in
Case 5, where the RW model was set on the steel plate having a larger friction, $\delta_{\text {footing }}$.

Munaf (1998) and Koseki et al. (2001) reported that the resultant force of the static earth pressure acting on the same RW model for tilting tests was, in a board sense, comparable with the theoretical value based on the M-O theory. This indicates that the difference between the experimental value of the shaking table tests and the value obtained using the M-O theory was mainly caused by the dynamic effect of the RW as well as the backfill; these factors are not considered in the M-O theory. That is, the angle of the failure plane and the resultant force of earth pressure for the shaking table tests cannot be obtained only by the force equilibrium of the soil wedge using the maximum acceleration and the backfill soil strength as assumed by the M-O theory. Further investigation of this issue is necessary, especially of the dynamic characteristics of the resultant force of seismic earth pressure.
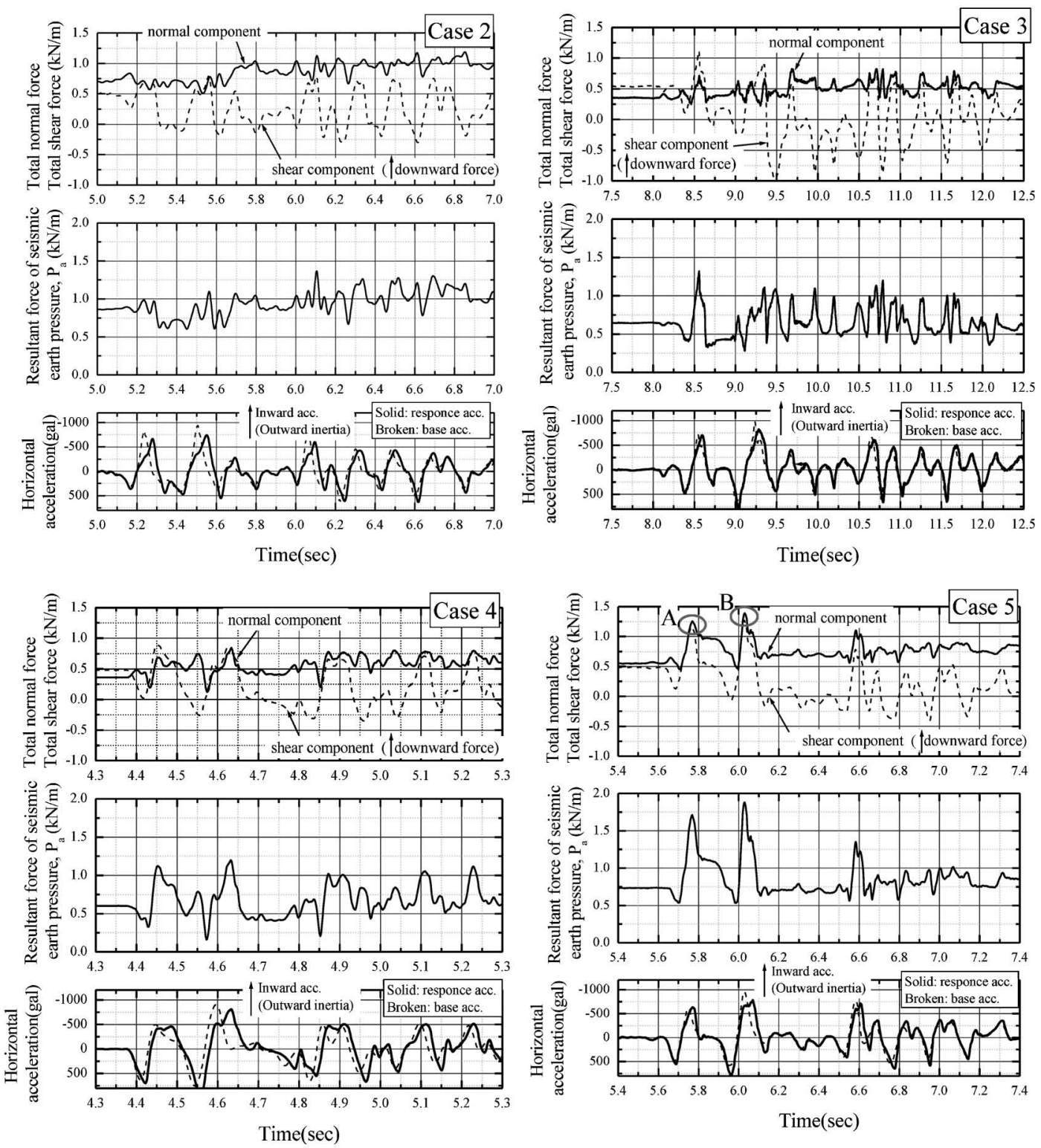

Fig. 15. Time history of resultant force of seismic earth pressure and acceleration 


\section{Dynamic Characteristics of Seismic Earth Pressure}

Figure 15 shows the time history of the resultant force of the seismic earth pressure, $P_{\mathrm{a}}$, total normal force, total shear force and horizontal acceleration in Cases 2, 3, 4 and 5 . In this figure, the positive shear force was defined as downward force. For all tests, the normal and shear forces increased simultaneously under negative response acceleration when the inertia force was oriented to the active direction, while the shear force decreased to a negative value under a passive condition. This indicates that the seismic active earth pressure applied obliquely downward. At this moment, the maximum of the normal and shear forces was on the same level, indicating that the maximum friction angle $\delta_{\text {wall }}$ at the interface between the backfill and the wall facing was around $40^{\circ}$ to $50^{\circ}$. This almost agrees with the friction angle that was employed in Figs. 13 and $14\left(\delta_{\text {wall }}=3 / 4 \phi_{\text {peak }}=38.25^{\circ}\right)$.

It can be seen that the phase relationship between the response acceleration of the backfill and the resultant force, $P_{\text {a }}$, was similar throughout the tests, in a broad sense. For example, the phase property in Cases 3 and 4 were quite similar to that in Case 5 in that the resultant force, $P_{\mathrm{a}}$, increased with an increase in the outward inertia, although the model was subjected to different predominant frequencies of shaking among these tests. This tendency was clear at the first large outward inertia force in Case 3, while it can be observed throughout the shaking in Case 4.

It can also be seen from this figure that the resultant force was larger in Case 5 than in Case 2, although the model was subjected to almost the same seismic excitation. In Case 5, the seismic earth pressure clearly increased when the inertia force was oriented toward the outside (active direction, Points A and B in Fig. 15), while only a slight increase can be seen in Case 2 . This difference may have been caused by the different degrees of seismic stability of the RW in Cases 2 and 5. In Case 2, when the inertia force was oriented outward, the RW moved outward more than the backfill, and the seismic earth pressure, which should have been mobilized by the "collision"' between the wall and the backfill, did not increase after the outward displacement of the RW. On the other hand, larger seismic earth pressure was mobilized by this "collision" in Case 5, where the RW model was set on the iron plate with larger friction. A similar tendency where the dynamic characteristics of seismic earth pressure were changed by the seismic stability of RW was also found in shaking table tests using different RW models (Watanabe et al., 1999).

This indicates that the seismic active earth pressure has an "upper limit", which is determined by the seismic stability of the RW. It seems that this "upper limit" of the earth pressure was determined by the force equilibrium of the soil wedge in the critical state when the RW lost its stability. Once the RW started to move outward, a stronger "collision" between the RW and the backfill could not be expected. The acceleration in the critical state, which was back-calculated from the measured seismic earth pressure was around 350-380 gal in Cases 1-4 and
Table 2. Maximum acceleration and critical acceleration of each test

\begin{tabular}{l|c|c|c}
\hline & $\begin{array}{c}\text { Maximum } \\
\text { base } \\
\text { acceleration } \\
\left(a_{\mathrm{h}, \mathrm{base}}\right)_{\max }\end{array}$ & $\begin{array}{c}\text { Maximum } \\
\text { response } \\
\text { acceleration } \\
\left(a_{\mathrm{h}, \mathrm{res}}\right)_{\max }\end{array}$ & $\begin{array}{c}\text { Critical acceleration back-calculated } \\
\text { from measured seismic } \\
\text { earth pressure } \\
\left(a_{\mathrm{h}, \mathrm{cr}}\right)_{\mathrm{EP}}\end{array}$ \\
\hline Case 1 & $963 \mathrm{gal}$ & $788 \mathrm{gal}$ & $375 \mathrm{gal}$ \\
\hline Case 2 & $935 \mathrm{gal}$ & $740 \mathrm{gal}$ & $356 \mathrm{gal}$ \\
\hline Case 3 & $982 \mathrm{gal}$ & $816 \mathrm{gal}$ & $378 \mathrm{gal}$ \\
\hline Case 4 & $906 \mathrm{gal}$ & $806 \mathrm{gal}$ & $358 \mathrm{gal}$ \\
\hline Case 5 & $952 \mathrm{gal}$ & $779 \mathrm{gal}$ & $471 \mathrm{gal}$ \\
\hline
\end{tabular}

470 gal in Case 5. This acceleration was estimated from the M-O theory using the peak value of the backfill soil strength, as shown in Fig. 14. The outward movement of the RW and the formation of the failure plane may begin around this acceleration. Table 2 summarizes all the test results, indicating that the critical acceleration back-calculated from the measured seismic earth pressure, $\left(a_{\mathrm{h}, \mathrm{cr}}\right)_{\mathrm{EP}}$, was considerably smaller than the maximum base acceleration, $\left(a_{\mathrm{h}, \text { base }}\right)_{\max }$, or the maximum response acceleration of the soil wedge, $\left(a_{\mathrm{h}, \mathrm{res}}\right)_{\max }$. Furthermore, it is likely that the angle of the failure plane was also determined by this "critical acceleration."

The dynamic characteristic of the seismic earth pressure observed through these tests can be summarized as follows:

1. Seismic active earth pressure was strongly affected by the seismic stability of the RW. It increased with the increase in the seismic stability of the RW, indicating that a stronger "collision" between the RW and the backfill was mobilized. However, in a broad sense, the effect of the predominant frequency of shaking on the phase relationship between the response acceleration of the backfill and the seismic earth pressure was limited. Seismic earth pressure increased with an increase in the outward inertia throughout the tests.

2. Seismic active earth pressure exhibited an "upper limit," which depended on the seismic stability of the RW. It seemed that this "upper limit" was determined by the force equilibrium of the soil wedge at the critical state when the RW lost its stability. In addition, it is likely that the angle of the failure plane was also determined at this critical state. Further investigation of this issue is necessary.

In order to verify the inference that the "upper limit", of the seismic active earth pressure and the angle of failure plane are determined by the force equilibrium of the soil wedge at the critical state, it is necessary to investigate the following two points:

1. The moment of formation of the failure plane during shaking

2. The relation between the external force and the resistance force acting on the RW during shaking

These two points will be discussed in the following two sections. 

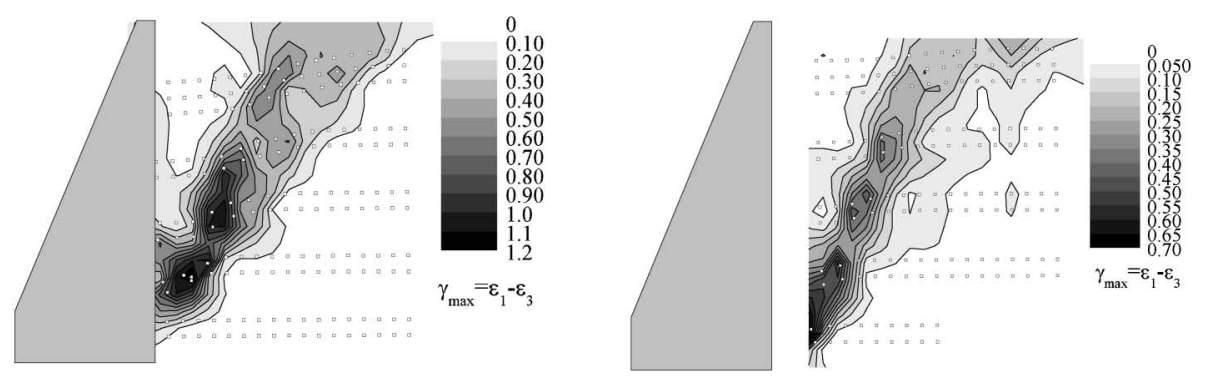

$<$ Case $2>$

$<$ Case $3>$

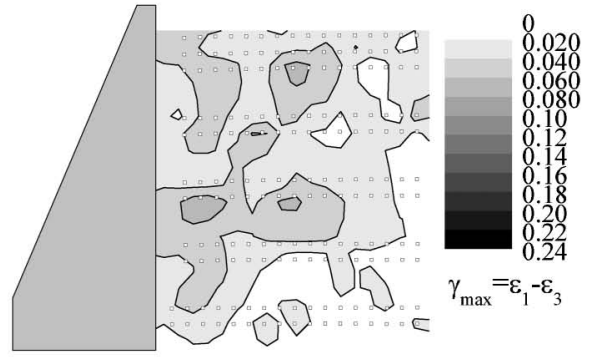

$<$ Case $4>$

Fig. 16. Distribution of maximum shear strain in backfill during shaking (at sixth peak inertia force state)

\section{Precise Observation of Formation of Failure Plane}

Figure 16 shows the maximum shear strain distribution of the backfill obtained by the image processing system in Cases 2, 3 and 4. The strain distribution was obtained when the sixth peak acceleration state inducing outward inertia was oriented toward the active direction (Point 6 in Fig. 4). The maximum shear strain was calculated from the isoparametric element, which was composed of four adjacent targets set at intervals of $25 \mathrm{~mm}$. Clear strain localization was observed in Cases 2 and 3 where the displacement of the RW was large, while the strain localization was not so clear at this stage in Case 4. Progressive failure from the heel of the RW toward the surface of the backfill can also be seen from these figures. This is because, as seen from Fig. 5, the major failure mode of the RW was sliding for these tests; thus, the strain became larger in the lower part than that in the upper part of the backfill.

Figure 17 shows the time history of the displacement of the soil wedge along the failure plane, $u_{\mathrm{s}}$, and the response acceleration of the soil wedge in Cases 2 and 3. This displacement was obtained by the relative displacement of a few targets in the vicinity of the failure plane at each height. The displacement of each target was measured by an image processing system. As schematically shown in Fig. 18, the displacement of the inside and the outside of the failure plane was obtained by extrapolating the displacement of two nearby targets along the failure plane, $u_{1}$ and $u_{2}$, for which $u_{\mathrm{s}}$ was the average relative displacement at each layer, namely, layers 4-13 in Fig. 18. It can be seen from Fig. 17(a) that $u_{\mathrm{s}}$ began to increase
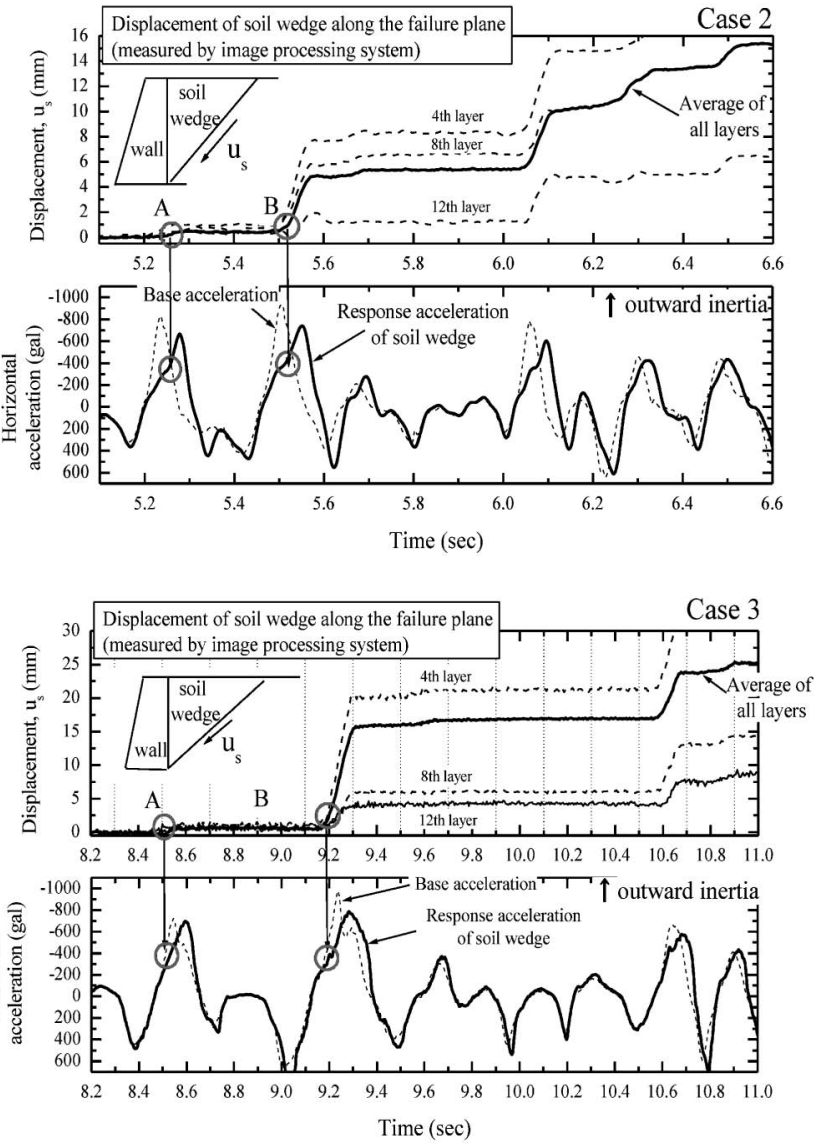

Fig. 17. Time history of acceleration and displacement of soil wedge along failure plane 


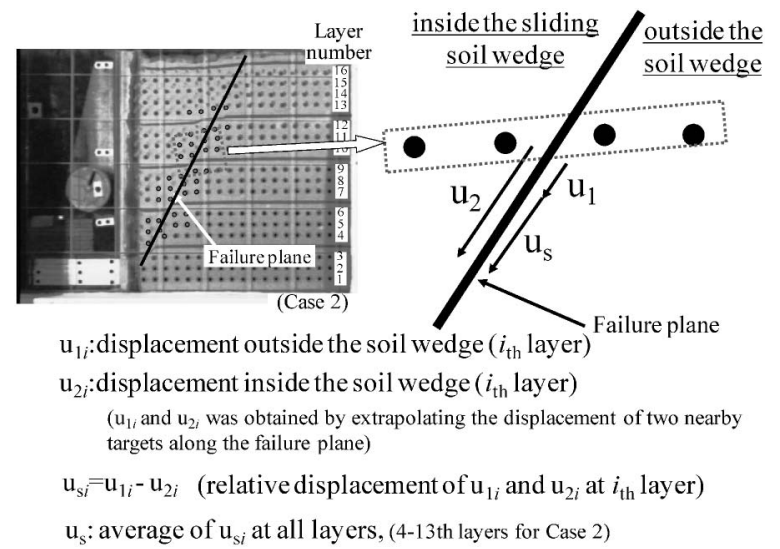

Fig. 18. Process of obtaining displacement of soil wedge along failure plane

when the response acceleration of the soil wedge $\left(a_{\mathrm{h}, \text { res }}\right)$ was around $350 \mathrm{gal}$ to $400 \mathrm{gal}$ for Case 2 (Point A for the first large outward inertia and Point B for the second inertia), which is smaller than the maximum base acceleration $\left(\left(a_{\mathrm{h}, \text { base }}\right)_{\max }=935 \mathrm{gal}\right)$. A similar tendency can be seen in Case 3 (Fig. 17(b)) and other tests. This indicates that the location of the failure plane had already been determined by the force equilibrium of the soil wedge before the response acceleration of soil wedge reached the maximum value. This may be because the RW had already lost its stability by this moment, resulting in the outward movement of the RW. In summary, the critical acceleration in which the RW began to move outward determined the angle of the failure plane. According to Nakajima et al. (2009), if RWs are constructed on soft ground, it is possible that the failure plane will start to form before the acceleration reaches the critical value. This is because the displacement of RWs, which causes strain localization in the backfill, increases by the shear deformation of the subsoil. However, the effect of the deformation of the subsoil on the formation of the failure plane is out of the scope of this study, where RW models were set on wellcompacted gravel.

On the other hand, the seismic active earth pressure should be increased after the development of a failure plane by strain softening behavior, as assumed in modified M-O theory. However, such a clear increase in seismic earth pressure after an increase in $u_{\mathrm{s}}$ (i.e., the displacement of the soil wedge along the failure plane) cannot be observed in Fig. 15, although the response acceleration of the soil wedge, $a_{\mathrm{h} \text {, res, }}$, is still increasing. For example, $u_{\mathrm{s}}$ had already increased by around $5.55 \mathrm{sec}$ for Case 2 (Fig. 17), but such a clear increase in seismic earth pressure cannot be observed at this moment (Fig. 15). Koseki et al. (2010) investigated this issue in detail by considering the negative pore air pressure which was measured clearly in the backfill of a leaning type of RW model during shaking. It was confirmed that the generation of negative pore air pressure, which is likely to be caused by the outward movement of the RW, causes a reduction in the seismic earth pressure. Broadly speaking, it is likely that the increase in seismic active earth pressure caused by the strain softening behavior and the decrease in seismic active earth pressure caused by the generation of negative pore air pressure were on the same level. A practical method to predict the seismic active earth pressure under a large seismic load will be discussed later.

\section{External Force and Resistance Force Acting on $R W$ during Shaking}

Figure 19 shows the time history of acceleration, wall displacement, external force and resistance force acting on the RW in Cases 2 and 3. The external force in the horizontal direction, $F$, was defined in this study as follows:

$$
F=W_{\mathrm{RW}} \times a_{\text {wall }}+P_{\text {a, horizontal }}
$$

where $W_{\mathrm{RW}}$ is the total weight of the RW, $a_{\text {wall }}$ is the response acceleration of the $\mathrm{RW}$ at the center of gravity and $P_{\mathrm{a} \text {, horizontal }}$ is the normal component of the resultant force of seismic earth pressure. $a_{\text {wall }}$ was obtained by interpolating the output of two accelerometers arranged at the top and bottom of the RW (Fig. 3). On the other hand, since the resistance force was not directly measured in this study, the maximum lateral resistance force, $R_{\max }$, was defined as follows:

$$
R_{\max }=\left(W_{\mathrm{RW}}+P_{\mathrm{a}, \text { vertical }}\right) \times \tan \left(\delta_{\text {footing }}\right)
$$

where $P_{\mathrm{a}}$, vertcial is the shear component of the resultant force of the seismic earth pressure and $\delta_{\text {bottom }}$ is the maximum frictional angle of the bottom of the base footing (Table 1). Since $P_{\text {a, vertcial }}$ changes during shaking (Fig. $15)$, the value of $R_{\max }$ is not constant. It can be seen from this figure that the external force increased with an increase in acceleration until it reached $R_{\max }$ (Point A in Fig. 19). Even though the acceleration was still increasing (after passing Point A), the external force could not exceed the maximum resistance force, indicating that the "upper limit" of the external force was determined by the maximum resistance force. A similar tendency was also observed for other shaking tests. Note that the maximum frictional angle at the bottom of the base footing,

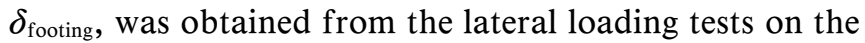
RW model under static conditions. However, the RW model exhibited tilting behavior during shaking to some extent, as can be seen from the time history of the top and bottom displacement (Fig. 19). At this moment, the resistance force, $R_{\max }$, may be mobilized largely at the toe of the base footing. That is why external force, F, exceeded the maximum resistance force temporarily when the RW model was tilting outward especially for Case 2 (Fig. 19). It should also be noted that the large seismic earth pressure measured in Case 5 (Fig. 14) was caused by the large friction angle at the bottom of the base footing, which mobilized a large resistance force.

These tests results indicate that the M-O theory always produces the possible maximum seismic earth pressure at the active state where the resistance force of the RW is sufficiently large. However, since the actual seismic earth pressure cannot exceed the resistance force, the actual 
a) Case 2
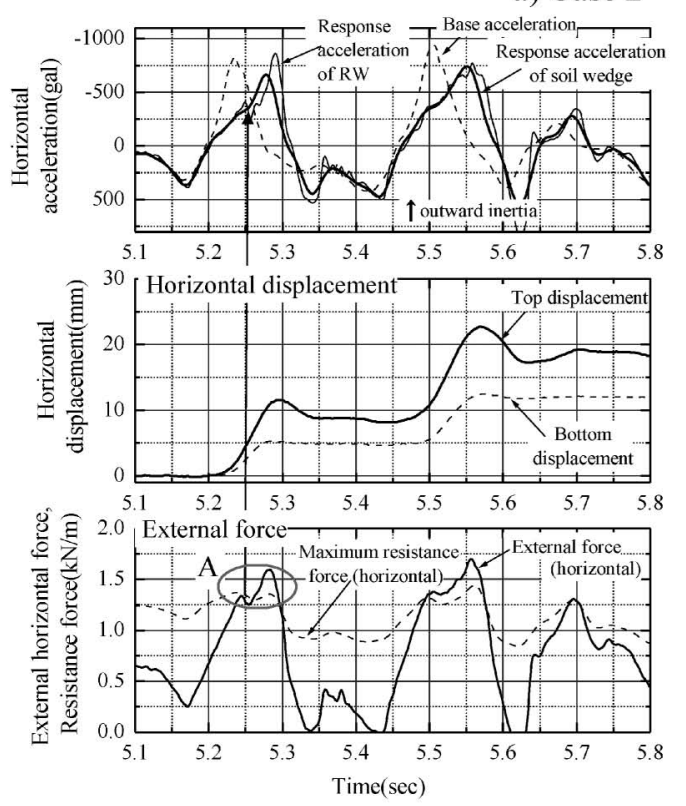

b) Case 3
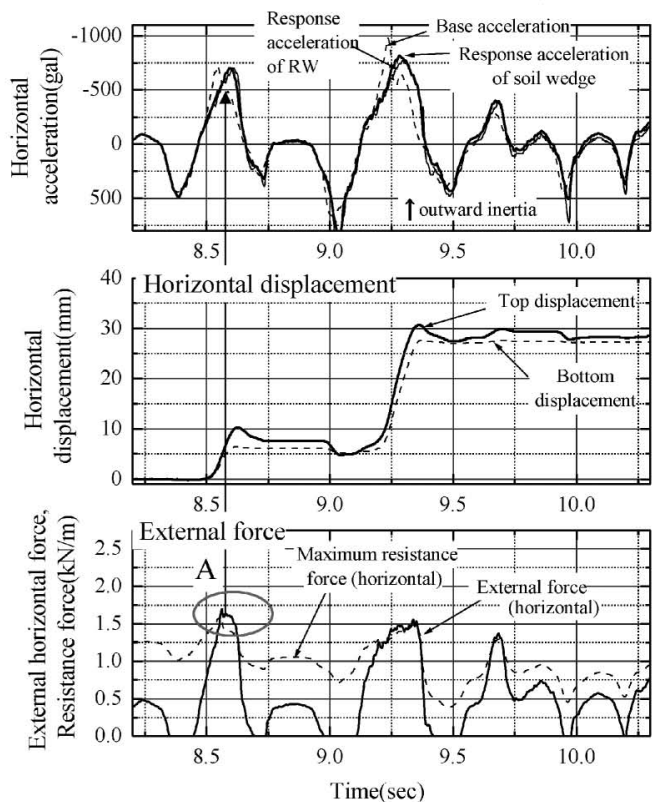

Fig. 19. Time history of acceleration, wall displacement, external force, and resistance force (a: Case 2, b: Case 3)

value usually becomes smaller than the value obtained by the M-O theory. Although these primary findings were obtained through small-scale shaking table model tests under a gravitational field, they are qualitatively applicable for predicting the seismic earth pressure for actual RWs under a large seismic load. This is because the effect of the progressive failure in the backfill on the active earth pressure is not so large compared to the effect on the bearing capacity or the slope failure. However, for the application of these findings, it is very important to evaluate the maximum resistance force which should be obtained by considering each failure mode of actual RWs, such as the bearing capacity, sliding and overturning.

It should also be noted from Fig. 19 that the displacement of the RW began to increase at Point A and accumulated rapidly during this period. Figure 20 shows the relationship between the external horizontal force and the horizontal displacement of the RW in Cases 2 and 3 around the first and second peak inertia force states. This figure shows more clearly that the displacement of the RW accumulated when the external force reached the "upper limit." Since this duration was longer in Case 3 with a low frequency of shaking $(2 \mathrm{~Hz})$ than in Case $2(5$ $\mathrm{Hz}$ ), the displacement became larger. For example, the duration between Points A and B in Fig. 20 was approximately $0.07 \mathrm{~s}$ in Case 2 and approximately $0.16 \mathrm{~s}$ in Case 3. The accumulation of the displacement during this period was around $10 \mathrm{~mm}$ in Case 2 and $22 \mathrm{~mm}$ in Case 3, indicating that the displacement was almost proportional to the duration when the external force reached the "upper limit." This result implies that the Newmark method (Newmark, 1965) may be applicable to the evaluation of the residual displacement of RWs. This will be discussed elsewhere.
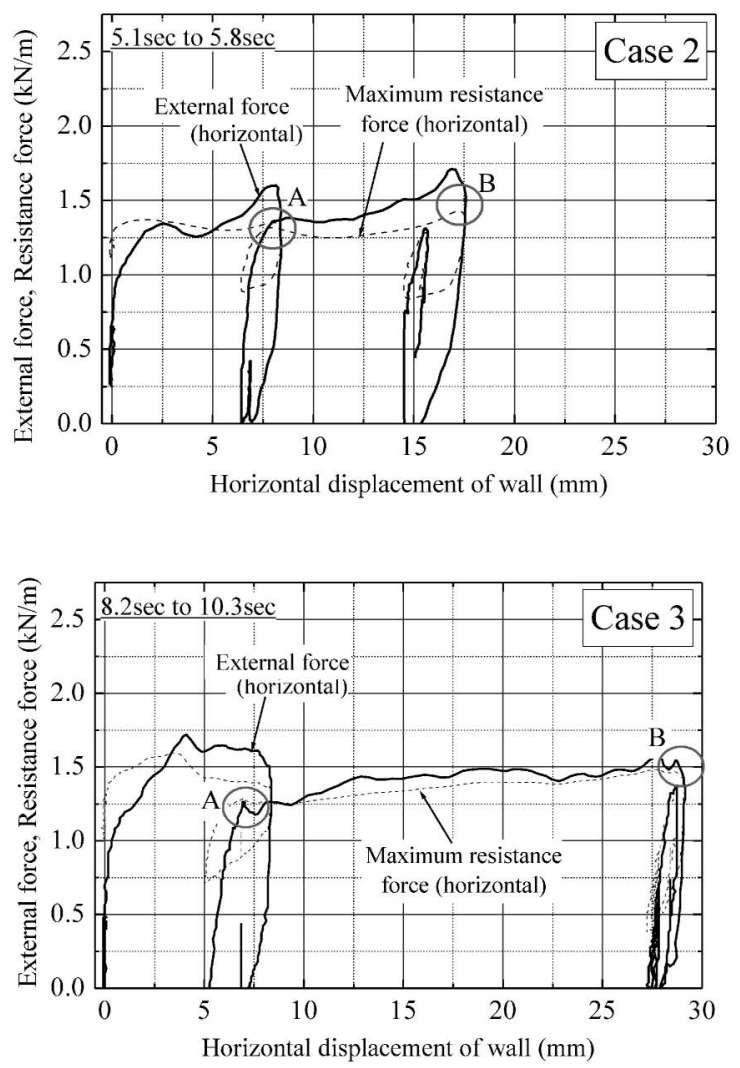

Fig. 20. Relationship between external force and horizontal displacement of $\mathbf{R W}$

New Method to Evaluate the Seismic Earth Pressure under a Large Seismic Load Using M-O Theory

The shaking table model tests under a large seismic load revealed that the resultant force of the seismic earth pressure was considerably smaller than that obtained by 
the M-O theory, and that the angle of the failure plane was larger than that obtained by the M-O theory. This is mainly due to the applicable limit of the M-O theory where the dynamic response of the RW is ignored. On the other hand, it was found that the seismic active earth pressure has an "upper limit," which is determined by the force equilibrium of the soil wedge in the critical state when the RW loses its stability.

Therefore, it should be suggested that the resultant force of the seismic earth pressure and the location of the failure plane under large seismic loads for practical designs can be evaluated by applying the critical acceleration, $a_{\mathrm{h} \text {, cr }}$, to the M-O theory. In this section, the practical applicability of the proposed method will be verified by applying this method to model tests.

The critical acceleration, $a_{\mathrm{h} \text {, cr }}$, was obtained by a stability analysis of the RW against the observed major failure pattern of each test (i.e., sliding or overturning). For each test, the critical acceleration was defined at the state where the calculated safety factor became equal to unity, and the safety factor was evaluated on the basis of the limit equilibrium method with the pseudo-static approach. By taking the major failure pattern of each model into consideration, we evaluated the safety factor against overturning in Case 1, and against sliding in Cases $2-5$.

The theoretical lateral earth pressure acting on the backface of the RW was calculated by the M-O theory. The earth pressure due to the self-weight of the backfill was assumed to be hydrostatically distributed along the wall height, and the pressure due to the surcharge applied on the surface of the backfill was assumed to be uniformly distributed. This assumption of hydrostatic distribution was adopted because it is widely used in current practice in Japan for designing RWs. The shear resistance angle $\phi$ of the backfill and subsoil layers was set to be equal to $\phi_{\text {peak }}\left(=51^{\circ}\right)$, and the frictional angle $\delta_{\text {wall }}$ was set to be equal to $3 / 4 \phi_{\text {peak }}$.

The critical acceleration, $a_{\mathrm{h}, \mathrm{cr}}$, against sliding in Cases 2-5 was obtained by using the friction angle between the bottom of the base footing and the iron plate, $\delta_{\text {footing }}$, which was obtained by conducting lateral loading tests (Table 1). The maximum lateral resistance force against sliding, $R_{\max }$, for these tests was obtained from Eq. (4).

On the other hand, in Case 1, the theoretical critical acceleration against overturning was obtained by assuming that overturning occurred around the center of the bottom surface of the base footing. Maximum resistance moment $M_{\max }$ was obtained by $M_{\mathrm{md}}$, which is employed in the current railway structure design standards (RTRI, 2000). In this design standard, the effect of the inclined load on the ultimate bearing capacity was considered by applying the inclination factors for the bearing capacity (Meyerhof, 1953; Meyerhof et al., 1987).

As shown in Table 3 , the critical acceleration obtained by the stability analysis, $a_{\mathrm{h}, \mathrm{cr}}$, and the critical acceleration back-calculated from the measured seismic earth pressure, $\left(a_{\mathrm{h}, \mathrm{cr}}\right)_{\mathrm{EP}}$ (Table 2$)$, were on the same level. They were also consistent with the response acceleration of the soil
Table 3. Critical acceleration obtained from stability analysis of each test

\begin{tabular}{l|c}
\hline & Critical acceleration obtained from stabilityanalysis, $a_{\mathrm{h}, \mathrm{cr}}$ \\
\hline Case 1 & $300 \mathrm{gal}$ \\
\hline Case 2 & $340 \mathrm{gal}$ \\
\hline Case 3 & $320 \mathrm{gal}$ \\
\hline Case 4 & $400 \mathrm{gal}$ \\
\hline Case 5 & $440 \mathrm{gal}$ \\
\hline
\end{tabular}

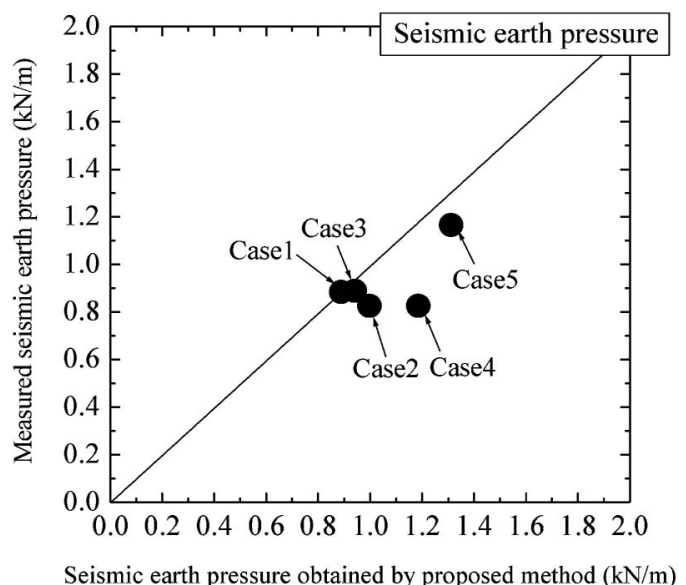

Fig. 21. Relationship between resultant force of seismic earth pressure obtained by proposed method and measured value

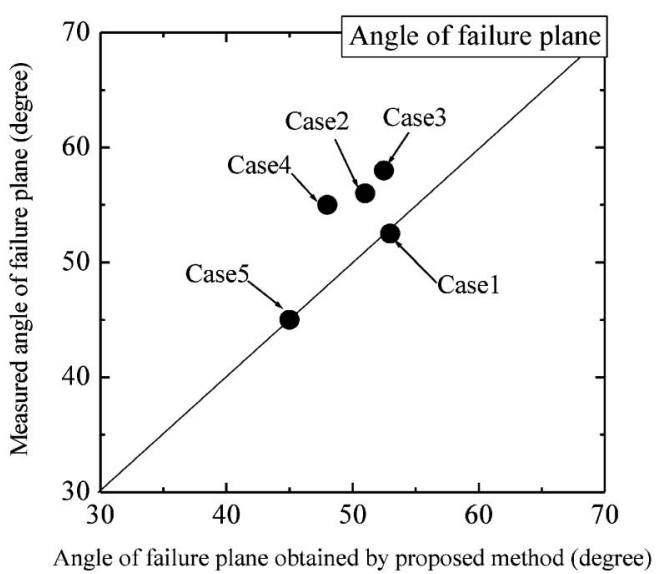

Fig. 22. Relationship between angle of failure plane obtained by proposed method and measured value

wedge $\left(a_{\mathrm{h}, \mathrm{res}}\right)$ when the displacement of the soil wedge, $u_{\mathrm{s}}$, began to increase (Fig. 17). Figure 21 shows the relationship between the measured seismic earth pressure and that obtained using the proposed method. The measured seismic earth pressure was obtained at the moment when $\left(a_{\mathrm{h}, \text { res }}\right)_{\max }$ was mobilized (Fig. 14). It can be seen from this figure that the proposed method provided a reasonable earth pressure under a large seismic load. As shown in Fig. 22, the angle of the failure plane measured in these tests was also consistent with the prediction based on the 
proposed method.

It should be noted that the critical acceleration was obtained from the simple stability analysis. These evaluation procedures for RW stability did not consider the dynamic effects in the shaking table tests, such as the amplification and the phase lag between the response acceleration and the base acceleration, as shown in Figs. 9 and 10, or the effect of progressive failure, as shown in Fig. 16. The seismic earth pressure obtained by the proposed method is underestimated, since it ignores the amplification of the response acceleration and the effect of progressive failure. On the other hand, it is overestimated, since it ignores the phase lag of the response acceleration. The overestimation of the seismic earth pressure in Case 4 (Fig. 21) is possibly due to the effect of the phase lag, which was significant compared to those in other tests subjected to a lower predominant frequency of shaking. Broadly speaking, it is likely that the effects of the aforementioned overestimation and underestimation were on the same level, except in Case 4.

Since the M-O theory simply employs the maximum acceleration of the input motion (around 700 gal in the current railway structure design standards in Japan), it often derives an unrealistic large earth pressure and a small angle of the failure plane under a large seismic load. This often causes practical problems in designing retaining structures to be constructed newly or in evaluating the seismic stability of existing retaining structures. However, the proposed method provides a reasonable earth pressure and angle of the failure plane under a large seismic load, which depends on the seismic stability of the RW. This is consistent with previous studies by Watanabe et al. (1999) and Nakamura (2006). Watanabe et al. (1999) found that the seismic earth pressure varied with the seismic stability of the RW. Nakamura (2006) pointed out that the maximum acceleration for applying the M-O theory to the practical design of an RW should be around 400 gal. This is based on the centrifuge model tests of gravity-type RWs.

On the other hand, the residual displacement of RWs is also affected by the seismic stability of walls; therefore, the aforementioned method for evaluating the seismic earth pressure rationally should be applied to the design of structural members of RWs. The residual displacement of RWs should be evaluated rationally by other methods. This is one of the remaining issues for establishing seismic design procedures for RWs.

\section{CONCLUSIONS}

In this study, a series of shaking table tests for a RW under a large seismic load were performed and the following conclusions were drawn.

1. The seismic active earth pressure acting on the RW was considerably smaller than that obtained by the Mononobe-Okabe (M-O) theory using the peak value of the backfill soil strength and the maximum response acceleration, particularly under a large seismic load. This is because the RW moved outward by the inertia force more than the backfill and the seismic earth pressure, which should have been mobilized by the collision between the wall and the backfill, did not increase after the outward displacement of the RW. This indicates that the seismic earth pressure was significantly affected by the seismic stability of the RW and cannot be obtained only by the force equilibrium of the soil wedge using the maximum acceleration, as is assumed in the M-O theory.

2. The location of the failure plane was steeper than the theoretical value, which was obtained by applying the maximum response acceleration and the peak soil strength to the M-O theory. This result is consistent with the actual observation of the failure plane formed in the backfill of the damaged railway RW after the Hyogo-ken Nambu earthquake.

3. The moment of the formation of the failure plane during shaking was precisely investigated using an image processing system. It was revealed that the displacement of the soil wedge began to increase before the response acceleration of the soil wedge reached the maximum. This indicates that the location of the failure plane had already been determined by the force equilibrium of the soil wedge before the response acceleration reached the maximum.

4. The relation between the external force and the resistance force acting on the RW during shaking was precisely investigated. It was found that the seismic active earth pressure had an upper limit, which was determined by the force equilibrium of the soil wedge at the critical state when the RW lost its stability. The M-O theory always provides a possible maximum seismic earth pressure at the active state where the resistance force of the RW is sufficiently large.

5. On the basis of the test results, it was suggested that the seismic earth pressure and the location of the failure plane under a large seismic load for practical designs can be evaluated by applying the critical acceleration to the $\mathrm{M}-\mathrm{O}$ theory. The critical acceleration can be easily obtained by the stability analysis of the RW against the major failure pattern.

6. The proposed method provides a reasonable earth pressure under a large seismic load, which depends on the seismic stability of the RW. It also provides a reasonable angle of the failure plane under a large seismic load, which depends on the seismic stability of the RW.

\section{ACKNOWLEDGMENTS}

The authors appreciate the assistance of Professor F. Tatsuoka of Tokyo University of Science, for his valuable suggestions regarding our research, and Mr. S. Morikoshi of Integrated Geotechnology Institute Limited, for his assistance in conducting the model tests.

\section{REFERENCES}

1) Ichihara, M. and Matsuzawa, H. (1973): Earth pressure during 
earthquake, Soils and Foundations, 13(4), 75-86.

2) Japan Road Association (2002): Specifications for Highway Bridges, Part V-Seismic Design, 65-68 (in Japanese).

3) Koseki, J., Tatsuoka, F., Munaf, Y., Tateyama, M. and Kojima, K. (1998a): A modified procedure to evaluate active earth pressure at high seismic loads, Soils and Foundations, Special Issue on Geotechnical Aspects of the January 171995 Hyogoken-Nambu Earthquake, 2, 209-216.

4) Koseki, J., Munaf., Y., Tatsuoka, F., Tateyama, M., Kojima, K. and Sato, T. (1998b): Shaking table and tilt table tests of geosynthetic-reinforced soil and conventional retaining wall, Geosynthetics International, 5(1-2), 73-96.

5) Koseki, J., Watanabe, K., Tateyama, M. and Kojima, K. (2001): Seismic earth pressures acting on reinforced-soil and conventional type retaining wall, Proc. of the International Symposium on Earth Reinforcement, 393-398.

6) Koseki, J., Kimhor, H., Nakajima, S., Mulmi, S., Watanabe, K. and Tateyama, M. (2010): Negative pore air pressure generation in backfill of retaining walls during earthquakes and its effect on seismic earth pressure, Soils and Foundations, 50(5), 747-755.

7) Meyerhof G. G. (1953): The bearing capacity of foundations under eccentric and inclined loads, Proc., 3rd International Conference on Soil Mechanics and Foundation Engineering, 1, Zurich, Switzerland, $440-445$.

8) Meyerhof G. G. and Koumoto T. (1987): Inclination factors for bearing capacity of shallow footings, Journal of Geotechnical Engineering, ASCE, 113(9), 1013-1018.

9) Mononobe, N. and Matsuo, H. (1929): On determination of earth pressure during earthquake, Proc. World Engineering Congress 9, Tokyo, 177-185.

10) Munaf, Y. (1998): Study on seismic performance of soil retaining walls by tilting and shaking table tests, Doctoral thesis, University of Tokyo.

11) Nakajima, S., Koseki, J., Watanabe, K. and Tateyama, M. (2009): A simplified procedure to evaluate earthquake-induced residual displacements of conventional type retaining walls, Soils and Foundations, 49(2), 287-303.

12) Nakamura, S. (2006): Reexamination of Mononobe-Okabe theory of gravity retaining walls using centrifuge model tests, Soils and Foundations, 46(2), 135-146.

13) Newmark, N.M. (1965): Effects of earthquake on dams and embankments, Geotechnique, 15, 139-159.

14) Okabe, S. (1924): General theory on earth pressure and seismic sta- bility of retaining wall and dam, Journal of Japan Society of Civil Engineers, 10 (6), 1277-1323.

15) Okamura, M. and Matsuo, O. (2002): A displacement prediction method for retaining walls under seismic loadings, Soils and Foundations, 42(1), 131-138.

16) Railway Technical Research Institute (1999): Earthquake Design Standard for Railway Structure, Maruzen (in Japanese).

17) Railway Technical Research Institute (2000): Railway Structure Design Standard for Foundations and Soil Retaining Structures (SI unit version), Maruzen (in Japanese).

18) Sherif, M. A., Ishibashi, I. and Lee, Y. S. (1982): Earth pressure against rigid retaining walls, Journal of the Geotechnical Engineering Division, ASCE, 108(GT5), 679-695.

19) Tatsuoka, F., Okahara, M., Tanaka, T., Tani, K., Morimoto, T. and Siddiquee, M. S. A. (1991): Progressive failure and particle size effect in bearing capacity of a footing on sand, Proc. of Geotechnical Engineering Congress 1991, (eds. by Colorado, USA, Mclean, F., Campbell, D. A. and Harris, D. W.) ASCE, Geotechnical Special Publication 27(2), 788-802.

20) Tatsuoka, F., Tateyama M. and Koseki, J. (1996): Performance of soil retaining walls for railway embankments, Soils and Foundations, Special Issue of Soils and Foundations on Geotechnical Aspects of the January 171995 Hyogoken-Nambu Earthquake, 311-324.

21) Tatsuoka, F., Koseki, J., Tateyama, M., Munaf., Y., and Horii, K. (1998): Seismic stability against high seismic loads of geosyntheticreinforced soil retaining structures, Keynote Lecture, Proc., 6th Int, Conf. on Geosynthetics, Atlanta.

22) Watanabe, K., Maeda, T., Kobayashi, Y. and Towhata, I. (1999): Shaking table tests on seismic earth pressure exerted on retaining wall model, Proc. of the 2nd International Conference on Earthquake Geotechnical Engineering, Lisbon, 1, 297-302.

23) Watanabe, K., Munaf, Y., Koseki, J., Tateyama, M. and Kojima, K. (2003): Behaviors of several types of model retaining walls subjected to irregular excitation, Soils and Foundations, 43(5), 13-27.

24) Watanabe, K., Koseki, J. and Tateyama, M. (2005): Application of high speed digital CCD cameras to observe static and dynamic deformation characteristics of sand, Geotechnical Testing Journal, ASTM, 28(5), 423-435.

25) Whitman, R. V. (1990): Seismic design and behavior of gravity retaining walls, Design and performance of earth retaining structures, Geotechnical Special Publication No. 25, ASCE, 817-840. 